\title{
Research on the Physical Attributes Evaluation Criterion of College Students
}

\author{
Yujie Shen, Jindong Chang \\ College of Physical Education Southwest University, Chongqing, China \\ Email: shenyj1977@163.com, changlai@163.com
}

Received October $9^{\text {th }}$, 2013; revised November $9^{\text {th }}$, 2013; accepted November $16^{\text {th }}, 2013$

\begin{abstract}
Copyright (c) 2014 Yujie Shen, Jindong Chang. This is an open access article distributed under the Creative Commons Attribution License, which permits unrestricted use, distribution, and reproduction in any medium, provided the original work is properly cited. In accordance of the Creative Commons Attribution License all Copyrights (C) 2014 are reserved for SCIRP and the owner of the intellectual property Yujie Shen, Jindong Chang. All Copyright $(0) 2014$ are guarded by law and by SCIRP as a guardian.
\end{abstract}

\begin{abstract}
Purpose: to improve the college students' enthusiasm to participate in physical training and thus enhance students' physical fitness; to provide the reference for the education administrative departments' decisions and further improving the college physical teaching in our city. Methods: the paper did analysis with the sample of 19 - 22 years old college students' health monitoring data in 2009 in Chongqing, applying the method of percentiles to establish the physical attributes evaluation criterion of college students in Chongqing. Results: develop the score sheets of single physical attributes' index evaluation, comprehensive evaluation and physical attributes evaluation form for the Han college students in Chongqing. Conclusion: the physical attributes score sheets, evaluation form are applicable to the college students in Chongqing, and they can be popularized to other universities in Chongqing.
\end{abstract}

Keywords: Physical Attributes; Evaluation Criterion; College Students

\section{Introduction}

Physical attributes refer to the body's abilities while doing exercise To some extent, these abilities can also be seen as the integrated representation of human body morphology and function level Physical attributes evaluation of college students is paid more and more attention by the physical educators. Therefore, how to use the result to give a comprehensive evaluation for the students' physical attributes is an important research task that needs to be solved in the physical fitness field and receive much attention from the sports workers. Since 1997, for various reasons, Chongqing has not established the physical attributes evaluation system for the local college students, which is entirely disproportionate to the social economic development of Chongqing. For this reason, the paper did analysis with the sample of three colleges' 7206 students health monitoring data in 2009 in Chongqing, and established the physical attributes score sheets, evaluation form for the college students in Chongqing according to the widely used evaluation methods. The goal of this research is to allow students to learn the place of the level of his/her physical fitness in the same age group, and enhance the students' motivation to exercise. Meanwhile, it can provide reference for the education administrative departments' decisions and further improving the college physical teaching in our city.

\section{Subject and Methods}

\section{Subjects}

The study adopt cluster sampling method according to the requirements of "2005 Implementation Plans of Physical Fit- ness and Health Investigation on National College Students”, and randomly selected 7206 Han students whom are aged 19 22 from Southwest University, Chongqing Normal University, and Chongqing Industry Polytechnic College. There are 3983 boys (1048 aged 19, 1236 aged 20, 748 aged 21, and 951 aged 22), 3223 girls (778 aged 19, 715 aged 20, 909 aged 21, and 821 aged 22).

\section{Test Methods and Content}

The study made physical attributes tests according to "2005 Inspection Detail Instruction of Physical Fitness and Health Investigation on National College Students”. The tests included 50-meter race, standing long jump, 1000-meter race (boys), 800 -meter race (girls), sit-and-reach, and throwing medicine ball.

\section{Statistic Evaluation Method}

The study employed the methods of percentiles to establish the single index and comprehensive evaluation criteria. The analysis was done with the help of SPSS. With the analysis of variance, physical attributes' indexes of all age groups of boys and girls showed no significant differences. So the data of age groups were merged according to the gender.

\section{Results}

\section{Establishment of Single Physical Attributes' Index Evaluation Criterion}

\section{Grading of Single Physical Attributes' Index Evaluation Criterion}

The grading of single physical attributes' index evaluation 


\section{Y. J. SHEN, J. D. CHANG}

criterion using time as the measuring unit (standing long jump, sit-and-reach, throwing medicine ball ) (Table 1) was similar to those the time was not used as the measuring unit (50-meter race, 1000 -meter race , 800-meter race), the two were different in the reverse rank order.

Establishment of Single Physical Attributes' Index Evaluation Criterion

The percentiles 3, 10, 25, 75, 90, 97 of boys' and girls' physical attributes were calculated respectively (Tables 2 and
3). Later, the evaluation forms of physical fitness were established (Tables 4, 5).

Establishment of Physical Attributes Comprehensive Evaluation Criterion

Physical attributes comprehensive evaluation was converting the results of the five physical attributes' indexes into the unified scores, and then graded the total points of the five physical attributes' indexes (Tables 6, 7).

1) The differences of percentiles 3 and 97 of boys' and girls'

Table 1.

Grading of Single Physical Attributes’ Index Evaluation Criterion not using Time as the Measuring Unit.

\begin{tabular}{ccc}
\hline Grading & Criterion & Percentage/\% \\
\hline High & $\mathrm{Xi}>\mathrm{P}_{90}$ & 10 \\
Better than Average & $\mathrm{P}_{90}>\mathrm{Xi}>\mathrm{P}_{75}$ & 50 \\
Middle & $\mathrm{P}_{75}>\mathrm{Xi}>\mathrm{P}_{25}$ & 15 \\
Lower than Average & $\mathrm{P}_{25}>\mathrm{Xi}>\mathrm{P}_{10}$ & 10 \\
Low & $\mathrm{Xi}<\mathrm{P}_{10}$ & 15 \\
\hline
\end{tabular}

Table 2 .

Percentiles of Physical Attributes of Boys in Chongqing.

\begin{tabular}{ccccccc}
\hline Index & $\mathrm{P}_{3}$ & $\mathrm{P}_{10}$ & $\mathrm{P}_{25}$ & $\mathrm{P}_{75}$ & $\mathrm{P}_{90}$ & $\mathrm{P}_{97}$ \\
\hline 50-Meter Race/s & 8.6 & 8.0 & 7.6 & 7.0 & 6.8 & 6.5 \\
Standing Long Jump/cm & 187.0 & 205.0 & 215.0 & 241.0 & 256.0 & 270.0 \\
1000-Meter Race/s & 316.0 & 302.0 & 265.6 & 227.0 & 214.0 & 200.5 \\
Sit-and-Reach /cm & 1.7 & 4.5 & 10.0 & 18.0 & 21.1 & 24.2 \\
Throwing Medicine Ball/m & 6.5 & 7.4 & 7.9 & 9.8 & 10.0 & 12.0 \\
\hline
\end{tabular}

Table 3 .

Percentiles of Physical Attributes of Girls in Chongqing.

\begin{tabular}{ccccccc}
\hline Index & $\mathrm{P}_{3}$ & $\mathrm{P}_{10}$ & $\mathrm{P}_{25}$ & $\mathrm{P}_{75}$ & $\mathrm{P}_{90}$ & $\mathrm{P}_{97}$ \\
\hline 50-Meter Race/s & 10.0 & 9.6 & 9.2 & 8.6 & 8.2 & 7.9 \\
Standing Long Jump/cm & 143.0 & 158.0 & 161.0 & 180.0 & 198.0 & 220.0 \\
800-Meter Race/s & 282.0 & 260.0 & 250.0 & 226.0 & 216.4 & 206.0 \\
Sit-and-Reach/cm & 4.1 & 9.3 & 12.8 & 18.8 & 21.2 & 24.0 \\
Throwing Medicine Ball/m & 3.9 & 4.2 & 4.8 & 6.1 & 6.8 & 8.1 \\
\hline
\end{tabular}

Table 4.

Evaluation Criterion of Physical Attributes of Boys in Chongqing.

\begin{tabular}{cccccc}
\hline Index & High & Better than Average & Middle & Lower than Average & Low \\
\hline 50-Meter Race/s & $<6.8$ & $6.8-7.0$ & $7.1-7.6$ & $7.7-8.0$ & $>8.0$ \\
Standing Long Jump/cm & $>256.0$ & $241.0-256.0$ & $215.0-240.9$ & $205.0-214.9$ & $<205.0$ \\
1000-Meter Race/s & $<214.0$ & $214.0-227.0$ & $227.0-265.6$ & $265.6-302.0$ & $>302.0$ \\
Sit-and-Reach/cm & $>21.1$ & $18.0-21.1$ & $10.0-17.9$ & $4.5-9.9$ & $<4.5$ \\
Throwing Medicine Ball/m & $>10.0$ & $9.8-10.0$ & $7.9-9.7$ & $7.4-7.8$ & $>7.4$ \\
\hline
\end{tabular}

Table 5.

Evaluation Criterion of Physical Attributes of Girls in Chongqing.

\begin{tabular}{|c|c|c|c|c|c|}
\hline Index & High & Better than Average & Middle & Lower than Average & Low \\
\hline 50-Meter Race/s & $<8.2$ & $8.6-8.2$ & $8.7-9.2$ & $9.3-9.6$ & $>9.6$ \\
\hline Standing Long Jump/cm & $>198.0$ & $180.0-198.0$ & $161.0-179.9$ & $158.0-160.9$ & $<158.0$ \\
\hline 800-Meter Race/s & $<216.4$ & $216.4-226.0$ & $226.1-250.0$ & $260.0-250.1$ & $>260.0$ \\
\hline Sit-and-Reach/cm & $>21.2$ & $18.8-21.2$ & $12.8-18.7$ & $9.3-12.7$ & $<9.3$ \\
\hline Throwing Medicine Ball/m & $>6.8$ & $6.1-6.8$ & $4.8-6.0$ & $4.2-4.7$ & $<4.2$ \\
\hline
\end{tabular}


Table 6.

Score Sheet of Physical Attributes' Index for the College Students in Chongqing.

\begin{tabular}{|c|c|c|c|c|c|c|c|c|c|c|}
\hline \multirow{2}{*}{ Score } & \multicolumn{2}{|c|}{ 50-Meter Race/s } & \multicolumn{2}{|c|}{ Standing Long Jump/cm } & \multicolumn{2}{|c|}{$\begin{array}{c}\text { Throwing Medicine } \\
\text { Ball/s }\end{array}$} & \multicolumn{2}{|c|}{$\begin{array}{l}\text { 1000-Meter Race (boys)/s, } \\
\text { 800-Meter Race (girls)/s }\end{array}$} & \multicolumn{2}{|c|}{ Sit-and-Reach $/ \mathrm{cm}$} \\
\hline & Boy & Girl & Boy & Girl & Boy & Girl & Boy & Girl & Boy & Girl \\
\hline 1 & 8.6 & 10.0 & 187.0 & 143.0 & 6.5 & 3.9 & 316.0 & 282.0 & 1.7 & 4.1 \\
\hline 2 & 8.5 & 9.9 & 191.4 & 147.1 & 6.8 & 4.1 & 311.0 & 278.0 & 2.9 & 5.2 \\
\hline 3 & 8.4 & 9.8 & 195.7 & 151.1 & 7.1 & 4.3 & 305.9 & 274.0 & 4.1 & 6.2 \\
\hline 4 & 8.3 & 9.7 & 200.1 & 155.2 & 7.4 & 4.6 & 300.9 & 270.0 & 5.2 & 7.3 \\
\hline 5 & 8.2 & 9.6 & 204.5 & 159.2 & 7.7 & 4.8 & 295.9 & 266.0 & 6.4 & 8.3 \\
\hline 6 & 8.1 & 9.5 & 208.9 & 163.3 & 8.0 & 5.0 & 290.9 & 262.0 & 7.6 & 9.4 \\
\hline 7 & 7.9 & 9.3 & 213.2 & 167.3 & 8.2 & 5.2 & 285.8 & 258.0 & 8.8 & 10.4 \\
\hline 8 & 7.8 & 9.2 & 217.6 & 171.4 & 8.5 & 5.4 & 280.8 & 254.0 & 10.0 & 11.5 \\
\hline 9 & 7.7 & 9.1 & 222.0 & 175.4 & 8.8 & 5.7 & 275.8 & 250.0 & 11.1 & 12.5 \\
\hline 10 & 7.6 & 9.0 & 226.3 & 179.5 & 9.1 & 5.9 & 270.7 & 246.0 & 12.3 & 13.6 \\
\hline 11 & 7.5 & 8.9 & 230.7 & 183.5 & 9.4 & 6.1 & 265.7 & 242.0 & 13.5 & 14.6 \\
\hline 12 & 7.4 & 8.8 & 235.1 & 187.6 & 9.7 & 6.3 & 260.7 & 238.0 & 14.7 & 15.7 \\
\hline 13 & 7.3 & 8.7 & 239.4 & 191.6 & 10.0 & 6.5 & 255.6 & 234.0 & 15.9 & 16.7 \\
\hline 14 & 7.2 & 8.6 & 243.8 & 195.7 & 10.3 & 6.8 & 250.6 & 230.0 & 17.0 & 17.8 \\
\hline 15 & 7.1 & 8.5 & 248.2 & 199.7 & 10.6 & 7.0 & 245.6 & 226.0 & 18.2 & 18.8 \\
\hline 16 & 7.0 & 8.4 & 252.6 & 203.8 & 10.9 & 7.2 & 240.6 & 222.0 & 19.4 & 19.9 \\
\hline 17 & 6.8 & 8.2 & 256.9 & 207.8 & 11.1 & 7.4 & 235.5 & 218.0 & 20.6 & 20.9 \\
\hline 18 & 6.7 & 8.1 & 261.3 & 211.9 & 11.4 & 7.6 & 230.5 & 214.0 & 21.8 & 22.0 \\
\hline 19 & 6.6 & 8.0 & 265.7 & 215.9 & 11.7 & 7.9 & 225.5 & 210.0 & 22.9 & 23.0 \\
\hline 20 & 6.5 & 7.9 & 270.0 & 220.0 & 12.0 & 8.1 & 220.5 & 206.0 & 24.1 & 24.1 \\
\hline
\end{tabular}

Table 7.

Comprehensive Evaluation Criterion of Physical Attributes’ Index for the College Students in Chongqing.

\begin{tabular}{cccccc}
\hline Gender & High & Better than Average & Middle & Lower than Average & Low \\
\hline Boy & $>75$ & $68-75$ & $43-67$ & $33-42$ & $<33$ \\
Girl & $>69$ & $59-69$ & $40-59$ & $31-39$ & $<31$ \\
\hline
\end{tabular}

physical attributes were calculated respectively, then divided by 19 and obtained the value when every point added or decreased.

2) Dividing the evaluation criterion of single physical attributes' index into 20 score sections, the total score was 20. The result of percentiles 97 of physical attributes' index evaluation criterion not using time as the measuring unit was 20; there is a corresponding drop of one score when a section score decreased. The result of percentiles 3 of physical attributes' index evaluation criterion using time as the measuring unit was 20; there is a corresponding drop of one score when a section score increased.

3) Obtain the summation of the results of every student's physical attributes' indexes.

4) Calculating the percentiles 10, 25, 5, 90 of the total scores of boys' and girls' physical attributes' indexes and establish the comprehensive evaluation criterion.

\section{Usage of Evaluation Method}

1) Identifying the score sheets of single physical attributes' index and physical attributes evaluation form according to the gender, and find the corresponding scores and grade.

2) Comprehensive evaluation of physical attributes is calculating the total points of the single physical attributes' indexes, and then identifies the grade from the corresponding comprehensive evaluation form of physical attributes' index.

\section{Conclusions}

1) In this work, through the measurements of physical attributes' indexes of three colleges' 7206 Han students in 2009 in Chongqing, we established the physical attributes evaluation criterion for college students in Chongqing according to the method of percentile.

2) The physical attributes score sheets, evaluation form are applicable to the college students in Chongqing, and they can be popularized to other universities in Chongqing.

\section{Acknowledgements}

This research project was supported by the Fundamental Research Funds for the Central Universities of Southwest Univer- 
sity (SWU1109071), the Humanities and Social Science Research Youth Foundation of the Ministry of Education in China (Grant No. 12YJC880005) and Chongqing Higher Education Reform Project (No. 120388). Here the authors would like to express heartfelt thanks.

\section{REFERENCES}

Arnason, A., Sigurdsson, S. B., \& Gudmundsson, A. (2004). Physical fitness, injuries, and team performance in soccer. Medicine and Science in Sports and Exercise, 36, 278-285. http://dx.doi.org/10.1249/01.MSS.0000113478.92945.CA

Bergamin, M., Zanuso, S., \& Alvar, B. A. (2012). Is water-based exercise training sufficient to improve physical fitness in the elderly? European review of Aging and Physical Activity, 9, 129-141. http://dx.doi.org/10.1007/s11556-012-0097-1

Bunce, D. (2001). The locus of age $x$ health-related physical fitness interactions in serial choice responding as a function of task complexity: Central processing or motor function? Experimental Aging Research, 27, 103-122. http://dx.doi.org/10.1080/713842729

Cuenca-Garcia, M., Jago, R., \& Shield, J. P. H. (2012). How does physical activity and fitness influence glycaemic control in young people with Type 1 diabetes? Diabetic Medicine, 29, e369-e376. http://dx.doi.org/10.1111/j.1464-5491.2012.03740.x

Granados, C., Izquierdo, M., \& Ibanez, J. (2008). Effects of an entire season on physical fitness in elite female handball players. Medicine and Science in Sports and Exercise, 40, 351-361.

http://dx.doi.org/10.1249/mss.0b013e31815b4905

Kang, H. S., Matsuo, T., \& Suzuki, M. (2004). Effects of light resistance exercise using dumbbells and rubber band with mild energy restriction on body composition and physical fitness in obese Korean women. Asia Pacific Journal of Clinical Nutrition, 13, 242-247.
Lu, W-D. (2006). SPSS for windows. Electronic Industry Press, 26-34.

Nagayama, H., Kimura, Y., \& Shimada, M. (2008). Relationship between daily steps and physical fitness in community-dwelling eldery. Japanese Journal of Physical Fitness and Sports Medicine, 57, 151162. http://dx.doi.org/10.7600/jspfsm.57.151

Martinez-Vizcaino, V. \& Sanchez-Lopez, M. (2008). Relationship between physical activity and physical fitness in children and adolescents. Revista Espanola de Cardiologia, 61, 108-111. http://dx.doi.org/10.1016/S1885-5857(08)60084-5

National sports institute of textbooks (1987). Sport theory. People's Sports Press, 232-233.

National sports institute of textbooks (1990). Sports statistics. People's Sports Press, 78-80.

National sports institute of textbooks (1997). Sports measurement and evaluation. People’s Sports Press, 162-211.

Nokes, N. (2009). Relationship between physical activity and aerobic fitness. Journal of Sports Medicine and Physical Fitness, 49, 136141.

Teoman, N., Ozcan, A., \& Acar, B. (2004). The effect of exercise on physical fitness and quality of life in postmenopausal women. Maturitas, 47, 71-77. http://dx.doi.org/10.1016/S0378-5122(03)00241-X

Van der Hoek, F. D., Stuive, I., \& Reinders-Messelink, H. A. (2012). Health-related physical fitness in Dutch children with developmental coordination disorder. Journal of Developmental and Behavioral Pediatrics, 33, 649-655.

http://dx.doi.org/10.1097/DBP.0b013e3182653c50

Yilmaz, I., Ergu, N., \& Konukman, F. (2009). The effects of water exercises and swimming on physical fitness of children with mental retardation. Journal of Human Kinetics, 21, 105-111. http://dx.doi.org/10.2478/v10078-09-0013-6

Zhang, H. H., Chen, Y., \& Lai, Q. (2009). Body composition and physical fitness in relation to body image. Journal of Sport \& Exercise Psychology, 31, S145-S146. 